\title{
Frequency, Tidal Volume, and Mean Airway Pressure Combinations that Provide Adequate Gas Exchange and Low Alveolar Pressure during High Frequency Oscillatory Ventilation in Rabbits
}

\author{
MICHAEL D. KAMITSUKA, BRUCE R. BOYNTON, DINA VILLANUEVA, \\ PATRICIA N. VREELAND, AND IVAN D. FRANTZ III \\ Tufts University School of Medicine, Department of Pediatrics, Floating Hospital for Infants and Children, New \\ England Medical Center, Boston, Massachusetts 02111
}

\begin{abstract}
We studied healthy and saline lavaged rabbits during high frequency oscillatory ventilation to determine what combination of frequency $(f)$, tidal volume $\left(V_{t}\right)$, and mean airway pressure $\left(\overline{\mathbf{P}}_{\mathrm{aw}}\right)$ produced the lowest peakto-peak alveolar pressure amplitude $\left(P_{\text {alv }}\right)$ and physiologic blood gas tensions. Sinusoidal volume changes were delivered through a tracheostomy by a piston pump driven by a linear motor. Tracheal pressure amplitude $\left(P_{t r}\right)$ was measured through a tracheal catheter and alveolar pressure amplitude was measured in a capsule glued to the right lower lobe. $\mathrm{PaO}_{2}, \mathrm{PaCO}_{2}, \mathrm{P}_{\mathrm{tr}}$, and $\mathrm{P}_{\mathrm{alv}}$ were measured at the following settings: $\mathrm{FiO}_{2}=0.5$, frequency $2-28 \mathrm{~Hz}, \mathrm{~V}_{\mathrm{t}} \mathrm{1-3}$ $\mathrm{mL} / \mathrm{kg}$ (50 150\% dead space) and $\overline{\mathrm{P}}_{\mathrm{aw}} 5-15 \mathrm{~cm} \mathrm{H} \mathrm{H}_{2} \mathrm{O}$. Many combinations of frequency and $V_{t}$ resulted in the same $\mathrm{PaO}_{2}$ and $\mathrm{PaCO}_{2} . \overline{\mathbf{P}}_{\mathrm{aw}}$ had a large effect on $\mathrm{P}_{\mathrm{alv}}$ and minimal effect on blood gas tensions. In lavaged rabbits, the composite variable $f \times V_{t}^{2}$ described the trends in $P_{a l v}$ and blood gas tensions. As the product of $f \times V_{t}^{2}$ increased, $\mathrm{PaO}_{2}$ initially increased and then decreased, whereas $\mathrm{PaCO}_{2}$ decreased and $P_{\text {alv }}$ increased. No single combination of frequency, $V_{t}$ and $\overline{\mathbf{P}}_{\mathrm{aw}}$ simultaneously provided the lowest $P_{\text {alv }}$ and physiologic blood gas tensions. Adequate blood gas tensions and low $P_{\text {alv }}$ were obtained at frequencies less than $12 \mathrm{~Hz}, \mathrm{a} V_{\mathrm{t}}$ of $2 \mathrm{~mL} / \mathrm{kg}$ and a $\overline{\mathrm{P}}_{\mathrm{aw}}$ of $10 \mathrm{~cm} \mathrm{H} \mathrm{H}_{2} \mathrm{O}$. In healthy and lavaged rabbits $\mathrm{PaO}_{2}$ increased and $\mathrm{PaCO}_{2}$ decreased as frequency increased at lower $\mathrm{V}_{t} \cdot \mathbf{P a O}_{2}$ decreased as frequency increased at higher $V_{t}$ in lavaged rabbits only. $P_{a l v}$ tended to be greater in lavaged rabbits. (Pediatr Res 27: 64-69, 1990)
\end{abstract}

\section{Abbreviations}

\section{f, frequency}

$V_{t}$, tidal volume

$\overline{\mathbf{P}}_{\text {aw }}$, mean airway pressure

$P_{\text {tr }}$, peak-to-peak tracheal pressure amplitude

$P_{\text {alv }}$, peak-to-peak alveolar pressure amplitude

HFOV, high frequency oscillatory ventilation

$\dot{\mathbf{V}}_{\text {osc, }}$ oscillatory ventilation

$\dot{\mathrm{V}}_{\mathrm{A}} / \dot{\mathrm{Q}}$, ventilation-perfusion ratio

$\dot{\mathrm{V}} \mathrm{CO}_{2}$, expired $\mathrm{CO}_{2}$

Received February 28, 1989; accepted September 7, 1989.

Correspondence Michael D. Kamitsuka, M.D., Box 44, Department of Pediatrics, Floating Hospital for Infants and Children, New England Medical Center, 750 Washington Street, Boston, MA 02111.

Supported by NIH Grant HL34616.
Selected effects of $f, V_{t}$, and $\bar{P}_{a w}$ on gas exchange and pressure amplitude have been studied previously in healthy and lung damaged animal models during HFOV. Oxygenation and ventilation have been shown to depend on frequency and $V_{t}(1,2)$. Previous work indicating there is a relationship between $\mathrm{CO}_{2}$ elimination and the product of oscillatory frequency and $\mathrm{V}_{\mathrm{t}}$ $\left[\dot{\mathrm{V} C O} \mathrm{C}_{2}=\mathrm{a}(\mathrm{f})^{\mathrm{b}}\left(\mathrm{V}_{\mathrm{t}}\right)^{\mathrm{c}}\right.$ where $\mathrm{a}, \mathrm{b}, \mathrm{c}$ are constants] $(3,4)$ led us to evaluate the relationship of arterial blood gas tensions to the product $f \times V_{t}^{2}(5)$. We observed that many combinations of frequency and $V_{t}$ produced equivalent blood gas tensions and that the composite variable $f \times V_{t}^{2}$ was a good descriptor of our mean arterial blood gas tensions during HFOV in healthy rabbits. Others have found that different combinations of frequency, $V_{t}$ and $\bar{P}_{\mathrm{aw}}$ can produce equivalent blood gas tensions $(3,4)$ but the resultant pressure swings in the trachea and alveolus may not be equivalent. Near the resonant frequency of the respiratory system, pressure swings in the alveolus may exceed those at the airway opening during $\operatorname{HFOV}(8,9)$. Allen et al. (10) reported that the ratio, $\mathrm{P}_{\mathrm{alv}} / \mathrm{P}_{\mathrm{ao}}$, increased as $\overline{\mathrm{P}}_{\mathrm{aw}}$ increased near the resonant frequency in excised rabbit lungs. Although increasing $\overline{\mathbf{P}}_{\mathrm{aw}}$ has not been shown to improve gas exchange in healthy animals (11) it does improve oxygenation in lung damaged animal models (12-14).

We wished to determine whether there is a combination of frequency, $\mathrm{V}_{\mathrm{t}}$ and $\overline{\mathrm{P}}_{\mathrm{aw}}$ that provides adequate blood gas tensions (i.e. the highest $\mathrm{PaO}_{2}$ and $\mathrm{PaCO}_{2}$ between 35 and 55 torr) and minimizes airway pressure amplitude. We examined systematically the combined effects of frequency, $V_{t}$ and $\bar{P}_{a w}$ on gas exchange and airway pressure swings during HFOV. Because of the previous conflicting results of $\overline{\mathrm{P}}_{\mathrm{aw}}$ effect on $\mathrm{PaO}_{2}$ in healthy and lung damaged animals, we also compared healthy and saline lavaged rabbits to determine how frequency, $V_{t}$ and $\overline{\mathrm{P}}_{a w}$ affected gas exchange and airway pressure swings in each model.

\section{MATERIALS AND METHODS}

Animal preparation. Ten juvenile male New Zealand White rabbits ranging in wt from 2.05 to $3.03 \mathrm{~kg}$ were studied. They were anesthetized with ketamine $(40 \mathrm{mg} / \mathrm{kg})$, acepromazine $(0.4$ $\mathrm{mg} / \mathrm{kg})$, and xylazine $(6 \mathrm{mg} / \mathrm{kg})$ by intramuscular injection. A tracheostomy was performed and a $3.0 \mathrm{~mm}$ inner diameter endotracheal tube was inserted. The animals were paralyzed with pancuronium $(0.8 \mathrm{mg})$ and ventilated. Sinusoidal volume changes were delivered through the endotracheal tube by a piston pump ventilator, driven by a linear motor (Hummingbird High Frequency Oscillator, Senko Medical Products, Tokyo, Japan). 
A high impedance bias flow $(6 \mathrm{~L} / \mathrm{m})$ supplied fresh humidified gas.

To produce a model of lung injury, we used a modification of Lachmann's pulmonary lavage technique (15). The rabbit was disconnected from the ventilator. Thirty $\mathrm{mL} / \mathrm{kg}$ of warmed saline were instilled through the endotracheal tube at a pressure of 50 $\mathrm{cm} \mathrm{H}_{2} \mathrm{O}$ and left for $10 \mathrm{~s}$ before drainage. The rabbit was reconnected to the ventilator. No sustained inflation was given before the next lavage. The lavage was repeated every $5 \mathrm{~min}$ until the $\mathrm{PaO}_{2}$ was less than 70 torr at $\mathrm{FiO}_{2}=1.0$. A median of two lavages (range 1-5) with 91\% (range $84-97 \%$ ) saline returned was required to reach the desired impairment of gas exchange. Body temperature was continuously monitored with a rectal temperature probe, and heating pads were used to maintain normothermia.

Measurement of $V_{t} . \mathrm{V}_{\mathrm{t}}$ was measured by integrating the flow signal from a no. 0 Fleisch pneumotachograph connected to a high fidelity differential pressure transducer (Celesco Transducer Products, Inc., Canoga Park, CA). The pneumotachograph was calibrated by adjusting the volume signal to equal a known $\mathrm{V}_{t}$ measured using a 30L pressure plethysmograph. The frequency response of the pneumotachograph-transducer system was studied by comparing its output with that of a pressure plethysmograph with a known dynamic response. The pneumotachograph had a flat amplitude response $\pm 16 \%$ from 3 to $30 \mathrm{~Hz}$. Correction factors were obtained from the frequency response curve. The ventilator stroke volume was adjusted appropriately to ensure that equal $V_{t}$ were delivered at all frequencies. Brusasco et al. (7) have shown that during HFOV, delivered gas volume to the lungs may differ from the stroke volume delivered by the piston pump. To validate that the $V_{t}$ delivered to the lung was equal to the $V_{t}$ measured by the pneumotachograph, we placed a tracheostomized rabbit in the plethysmograph and attached the endotracheal tube to the pneumotachograph and compared $V_{t}$ as measured by the plethysmograph and pneumotachograph at different frequencies. The plethysmograph and pneumotachograph measured $V_{t}$ were equal at frequencies of 4 and $28 \mathrm{~Hz}$ in the unlavaged rabbit. The pneumotachograph $V_{t}$ was no more than $5 \%$ more than the plethysmograph $\mathrm{V}_{\mathrm{t}}$ at a frequency of 28 $\mathrm{Hz}$ and equal at a frequency of $4 \mathrm{~Hz}$ in the lavaged rabbit.

Measurement of airway pressure. To measure peak-to-peak tracheal pressure amplitude about the mean $\mathrm{P}_{\mathrm{tr}}$, an air filled side hole catheter was placed next to the endotracheal tube so that its tip extended $0.5 \mathrm{~cm}$ beyond the endotracheal tube. Both the endotracheal tube and the pressure catheter were secured in place with an umbilical tie and sealed with cyanoacrylate glue to prevent air leaks.

To measure peak-to-peak alveolar pressure about the mean $\mathrm{P}_{\mathrm{alv}}$, a plastic capsule was attached to the visceral pleura of the right lower lobe in a modification of the method of Fredberg et al. (8). After the chest was opened at the 6th right intercostal space, the lungs were distended to $10 \mathrm{~cm} \mathrm{H}_{2} \mathrm{O}$. A thin sheet of soft plastic wrap, cut approximately $1 \mathrm{~cm}$ more than the capsule, was attached to the flat surface of the capsule with cyanoacrylate glue, and the plastic surface glued to the right lower lobe. Four punctures were made into the visceral pleura through the opening of the plastic capsule with a 20 -gauge needle to a depth of $3 \mathrm{~mm}$. The pressure transducer was then connected to the capsule. The chest remained open throughout the experiment. All pressures were measured using piezoresistive pressure transducers (Endevco Corp., San Juan Capistrano, CA).

From previous studies we have found that both transducer and catheter or transducer and alveolar capsule combinations had a flat amplitude response within $\pm 0.5 \%$ and a flat phase response $\pm 5^{\circ}$ from 0.5 to $30 \mathrm{~Hz}$ (16). All signals were amplified using Tektronix AM502 amplifiers (Tektronix Inc., Beaverton, OR) and displayed on an oscilloscope.

Measurement of arterial blood gas tensions. To obtain arterial blood samples, a 22-gauge angiocath was placed in the central ear artery. Blood gases tensions were measured with a BMS 3
Mark 2 Blood Micro System (Radiometer, Copenhagen, Denmark), and corrected to $37^{\circ} \mathrm{C}$. The electrodes were calibrated before each experiment with certified gas standards, and were accurate within $0.02 \%$. Duplicate measurements of blood samples never varied more than \pm 0.5 torr.

Experimental protocol. Five healthy and five lavaged rabbits were studied while receiving $\mathrm{FiO}_{2}$ of 0.5 . Similar combinations of frequency, $\mathrm{V}_{\mathrm{t}}$ and $\overline{\mathrm{P}}_{\mathrm{aw}}$ were studied but the order was randomized for each rabbit. Frequencies of $4,8,16,24 \mathrm{~Hz}$ and $\mathrm{V}_{\mathrm{t}}$ of 1 and $3 \mathrm{~mL} / \mathrm{kg}$ were studied in healthy rabbits. Frequencies of 2 , $12,20,24,28 \mathrm{~Hz}$ and $\mathrm{V}_{\mathrm{t}}$ of 1,2 , and $3 \mathrm{~mL} / \mathrm{kg}$ were studied in lavaged rabbits [a $\mathrm{V}_{\mathrm{t}}$ of $2.0 \mathrm{~mL} / \mathrm{kg}$ was estimated to equal physiologic dead space (1)]. At the largest $V_{t}(3 \mathrm{~mL} / \mathrm{kg})$, the maximum frequency attainable was $24 \mathrm{~Hz} . \overline{\mathrm{P}}_{\text {aw }}$ of $5.0,10.0$, and $15.0 \mathrm{~cm} \mathrm{H} \mathrm{H}_{2} \mathrm{O}$ were studied in each rabbit at every combination of frequency and $V_{t}$. To ensure that each combination of frequency, $V_{t}$ and $\bar{P}_{a w}$ was presented after the same volume history the lungs were inflated by increasing the $\overline{\mathrm{P}}_{\mathrm{aw}}$ to $20 \mathrm{~cm} \mathrm{H} \mathrm{H}_{2} \mathrm{O}$ for $10 \mathrm{~s}$ before each combination was studied. Arterial blood samples were drawn after an equilibration period (10-20 min) determined by the $f \times V_{t}^{2}$ at each setting. From our previous studies in healthy rabbits, we found that those settings with a $\times V_{t}^{2}$ less than $12.0 \mathrm{~mL}^{2} \mathrm{~kg}^{-2} \mathrm{~s}^{-1}$ required a 20 -min period for blood gas tensions to fully equilibrate. Blood gas tensions at settings with a higher $f \times V_{t}^{2}$ equilibrated faster and samples could be drawn after 10 min. $P_{\text {tr }}$ and $P_{\text {alv }}$ were measured just before changing to the next designated combination.

Analysis of data. To analyze the data statistically, we performed an $\mathrm{N}$-way analysis of variance evaluating the effects of frequency, $\mathrm{V}_{\mathrm{t}}$ and $\overline{\mathrm{P}}_{\text {aw }}$ on the dependent variables $\mathrm{PaO}_{2}, \mathrm{PaCO}_{2}$, and $\mathrm{P}_{\mathrm{alv}}$. We also performed a one way analysis of variance using Bonferroni comparison of dependent variable values at different frequencies, $V_{t}$ or $\bar{P}_{a w}$. All calculations were made using the computer program STATA version 1.5 (Computing Resource Center, Los Angeles, CA). Data are summarized as the mean of five rabbits $\pm \mathrm{SE}$ with statistical significance taken as $p<0.05$.

\section{RESULTS}

We will first present results describing how frequency, $V_{t}$ and $\overline{\mathrm{P}}_{\mathrm{aw}}$ affected blood gas tensions and alveolar pressure amplitude in saline lavaged rabbits and then indicate how the lavaged animals differ from normals. As frequency increased (Fig. 1), there was a trend for $\mathrm{PaO}_{2}$ to increase at a $\mathrm{V}_{\mathrm{t}}$ of $1 \mathrm{~mL} / \mathrm{kg}$, remain constant at $2 \mathrm{~mL} / \mathrm{kg}$ and decrease at a $\mathrm{V}_{\mathrm{t}}$ of $3 \mathrm{~mL} / \mathrm{kg}\left(\overline{\mathrm{P}}_{\mathrm{aw}}=10\right.$ $\mathrm{cm} \mathrm{H} \mathrm{H}_{2} \mathrm{O}$ ), but these trends were not statistically significant. $\mathrm{PaCO}_{2}$ significantly $(p<0.01)$ decreased with increasing frequency at all $\mathrm{V}_{\mathrm{t}} . \mathrm{P}_{\text {alv }}$ increased significantly $(p<0.05)$ with frequency at $\mathrm{V}_{\mathrm{t}}$ $=2 \mathrm{~mL} / \mathrm{kg}$ but not at $\mathrm{V}_{\mathrm{t}}=1$ or $3 \mathrm{~mL} / \mathrm{kg}\left(\overline{\mathrm{P}}_{\mathrm{aw}}=10 \mathrm{~cm} \mathrm{H} \mathrm{H}_{2} \mathrm{O}\right)$.

As $\mathrm{V}_{\mathrm{t}}$ increased $\left(\overline{\mathrm{P}}_{\mathrm{aw}}=10 \mathrm{~cm} \mathrm{H} \mathrm{H}_{2} \mathrm{O}\right)$ (Fig. 1), $\mathrm{PaO}_{2}$ was relatively unaffected, increasing significantly $(p<0.05)$ only at a frequency of $2 \mathrm{~Hz}$. $\mathrm{PaCO}_{2}$ significantly decreased with $\mathrm{V}_{\mathrm{t}}$ at all frequencies $(p<0.001)$ and $\mathrm{P}_{\text {alv }}$ significantly increased at all frequencies $(p$ $<0.05)$.

As $\overline{\mathrm{P}}_{\mathrm{aw}}$ increased at a $\mathrm{V}_{\mathrm{t}}$ of $2 \mathrm{~mL} / \mathrm{kg}$ (Fig. 2), there was a trend for $\mathrm{PaO}_{2}$ to increase, but this was significant $(p<0.01)$ only at 2 $\mathrm{Hz}, \mathrm{PaCO}_{2}$ was not affected, and $\mathrm{P}_{\text {alv }}$ amplitude significantly ( $p$ $<0.05)$ increased with $\overline{\mathrm{P}}_{\mathrm{aw}}$ at all frequencies $(p<0.001)$.

$\mathrm{P}_{\text {alv }}$ amplitude was low (<approximately $6 \mathrm{~cm} \mathrm{H}_{2} \mathrm{O}$ ) at every setting tested. The lowest $P_{\text {alv }}$ was observed when $V_{t}$ was $1 \mathrm{~mL} /$ $\mathrm{kg}$ (Fig. 1) and $\overline{\mathrm{P}}_{\mathrm{aw}}$ was $5 \mathrm{~cm} \mathrm{H}_{2} \mathrm{O}$ (Fig. 2) but values of $\mathrm{P}_{\mathrm{alv}}$ at a $\mathrm{V}_{\mathrm{t}}$ of $2 \mathrm{~mL} / \mathrm{kg}$ and a $\overline{\mathrm{P}}_{\mathrm{aw}}$ of $10 \mathrm{~cm} \mathrm{H}_{2} \mathrm{O}$ were not statistically different (Figs. 1 and 2).

$\mathrm{PaO}_{2}$ and $\mathrm{PaCO}_{2}$ from Figures 1 and 2 were replotted as functions of $\mathrm{f} \times \mathrm{V}_{\mathrm{t}}^{2}$ at all $\overline{\mathrm{P}}_{\mathrm{aw}}$ (Fig. 3). As the product $\mathrm{f} \times \mathrm{V}_{\mathrm{t}}{ }^{2}$ increased, $\mathrm{PaO}_{2}$ initially increased $(p<0.001)$ then decreased $(p$ $<0.05$ ) when the product was greater than $80 \mathrm{~mL}^{2} \mathrm{~kg}^{-2} \mathrm{~s}^{-1}$. As the product $\mathrm{f} \times \mathrm{V}_{\mathrm{t}}^{2}$ increased $\mathrm{PaCO}_{2}$ decreased $(p<0.001)$ and $\mathrm{P}_{\text {alv }}$ tended to increase for $\overline{\mathrm{P}}_{\mathrm{aw}} \leq 10 \mathrm{~cm} \mathrm{H}_{2} \mathrm{O}$ but was not statistically significant (Fig. 4). 

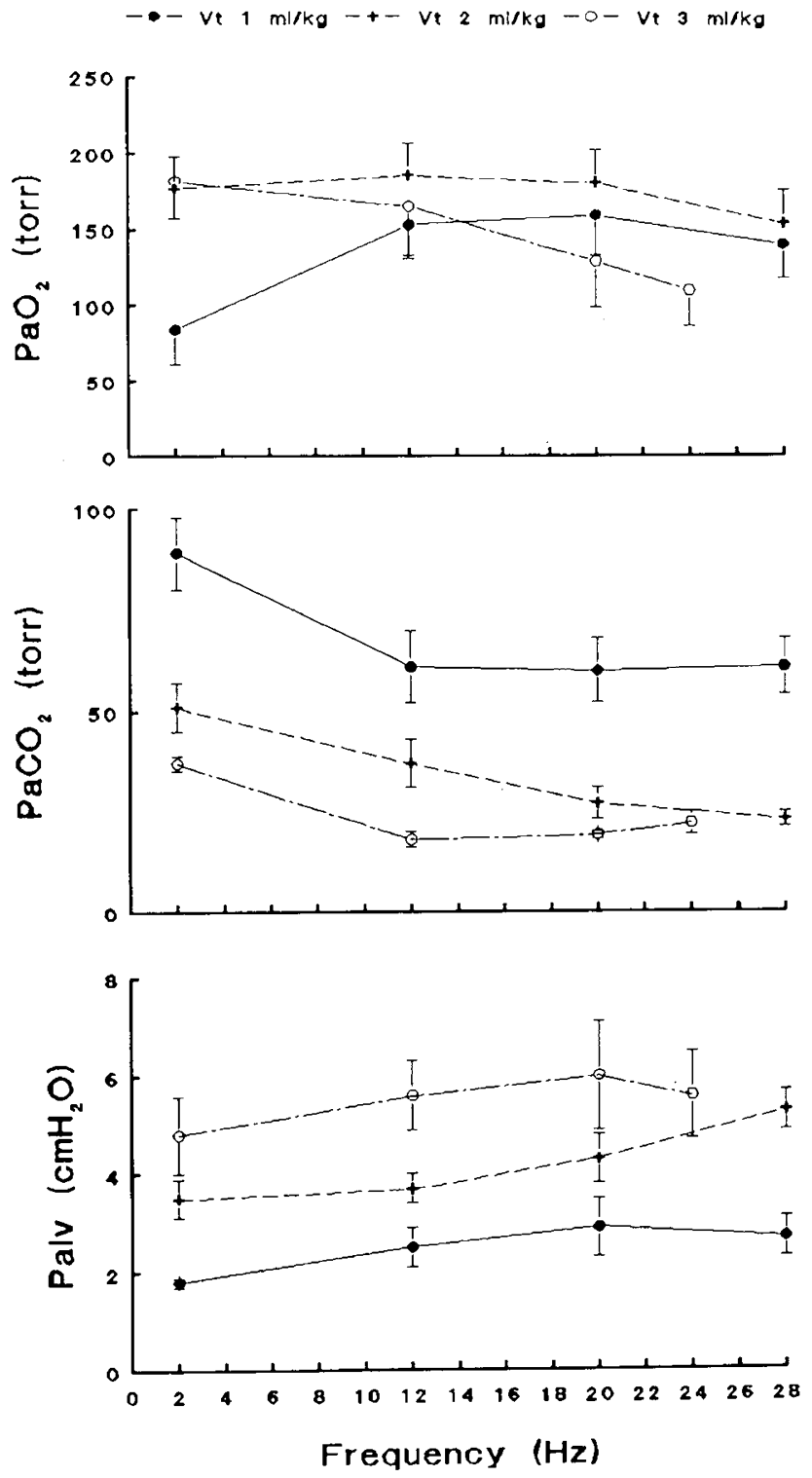

Fig. 1. $\mathrm{PaO}_{2}, \mathrm{PaCO}_{2}$, and $\mathrm{P}_{\text {alv }}$ as functions of frequency and $\mathrm{V}_{\mathrm{t}} \cdot \overline{\mathrm{P}}_{\mathrm{aw}}=$ $10 \mathrm{~cm} \mathrm{H}_{2} \mathrm{O} . \mathrm{F}_{\mathrm{i}} \mathrm{O}_{2}=0.5$. Each point is the mean of five lavaged rabbits $\pm \mathrm{SE}$.

Blood gas tensions were similar in healthy and lavaged rabbits (Fig. 5) but greater $P_{\text {alv }}$ amplitudes were required to obtain these blood gases in lavaged rabbits (Fig. 5). $\overline{\mathrm{P}}_{\mathrm{aw}}$ had little effect on $\mathrm{PaO}_{2}$ in healthy (Fig. $6 \mathrm{~A}$ ) or lavaged rabbits (Fig. $6 \mathrm{~B}$ ). Comparison of Figures 3 and 7 indicates differing relationships between $\mathrm{PaO}_{2}$ and $\mathrm{f} \times \mathrm{V}_{\mathrm{t}}^{2}$ in healthy and lavaged rabbits. $\mathrm{PaO}_{2}$ increased with $\mathrm{f} \times \mathrm{V}_{\mathrm{t}}{ }^{2}$ in healthy rabbits (Fig. 7) but decreased after an increase in lavaged rabbits (Fig. 3). $\mathrm{PaCO}_{2}$ decreased as $\mathrm{f} \times \mathrm{V}_{\mathrm{t}}{ }^{2}$ increased in both healthy and lavaged rabbits (Figs. 3 and 7). As $\mathrm{f} \times \mathrm{V}_{\mathrm{t}}{ }^{2}$ increased, $\mathrm{P}_{\mathrm{alv}}$ tended to increase for $\overline{\mathrm{P}}_{\mathrm{aw}}<10 \mathrm{~cm} \mathrm{H}_{2} \mathrm{O}$ in lavaged rabbits but showed no change in healthy rabbits (Fig. 8).

\section{DISCUSSION}

We observed many combinations of frequency and $V_{t}$ that resulted in the same $\mathrm{PaO}_{2}$ and $\mathrm{PaCO}_{2} . \overline{\mathrm{P}}_{\mathrm{aw}}$ had a large effect on $\mathrm{P}_{\text {alv }}$ amplitude but little effect on blood gas tensions. We found that in lavaged rabbits, the composite variable frequency multiplied by the square of the tidal volume $\left(f \times V_{t}^{2}\right)$ well described the trends in $\mathrm{P}_{\text {alv }}$ and blood gas tensions such that as the product of $\mathrm{f} \times \mathrm{V}_{\mathrm{t}}^{2}$ increased, $\mathrm{PaO}_{2}$ initially increased, then decreased, $\mathrm{PaCO}_{2}$ decreased and $\mathrm{P}_{\text {alv }}$ amplitude increased in lavaged rabbits. Therefore, we did not find one combination that simultaneously provided the lowest alveolar pressure amplitude and physiologic blood gas tensions. Compromises were necessary to reach either maximum blood gas tensions or minimal airway pressures. Combinations that simultaneously provide both a low $\mathrm{P}_{\text {alv }}$ amplitude and adequate blood gas tensions are frequencies less than $12 \mathrm{~Hz}$, a $V_{t}$ of $2 \mathrm{~mL} / \mathrm{kg}$ (approximately equal to dead space) and $\overline{\mathrm{P}}_{\mathrm{aw}}$ of $10 \mathrm{~cm} \mathrm{H}_{2} \mathrm{O}$.

Possible sources of errors that may have affected our results will be reviewed. All experiments were lengthy because of the time required for equilibration of $\mathrm{PaO}_{2}$ and $\mathrm{PaCO}_{2}$ values. The length of the experiment may have resulted in deterioration of the animal preparation resulting in deterioration of blood gas tensions toward the end of each experiment. Although $\mathrm{PaO}_{2}$ and $\mathrm{PaCO}_{2}$ appeared to be well maintained during the experiment, the animals did tend to develop a metabolic acidosis toward the end of the experiment. The random order of measurements should have served to minimize these effects. Although blood



Fig. 2. $\mathrm{PaO}_{2}, \mathrm{PaCO}_{2}, \mathrm{P}_{\text {alv }}$ as functions of frequency and $\overline{\mathrm{P}}_{\mathrm{aw}} \cdot \mathrm{V}_{\mathrm{t}}=2$ $\mathrm{mL} / \mathrm{kg}$. $\mathrm{FiO}_{2}=0.5$. Each point is the mean of five lavaged rabbits $\pm \mathrm{SE}$. 




Fig. 3. $\mathrm{PaO}_{2}$ and $\mathrm{PaCO}_{2}$ functions of $\mathrm{f} \times \mathrm{V}_{\mathrm{t}}^{2}$ for $\overline{\mathrm{P}}_{\mathrm{aw}} 5,10,15 \mathrm{~cm} \mathrm{H} \mathrm{H}_{2} \mathrm{O}$. $\mathrm{FiO}_{2}=0.5$. Each point is the mean of three to five lavaged rabbits.

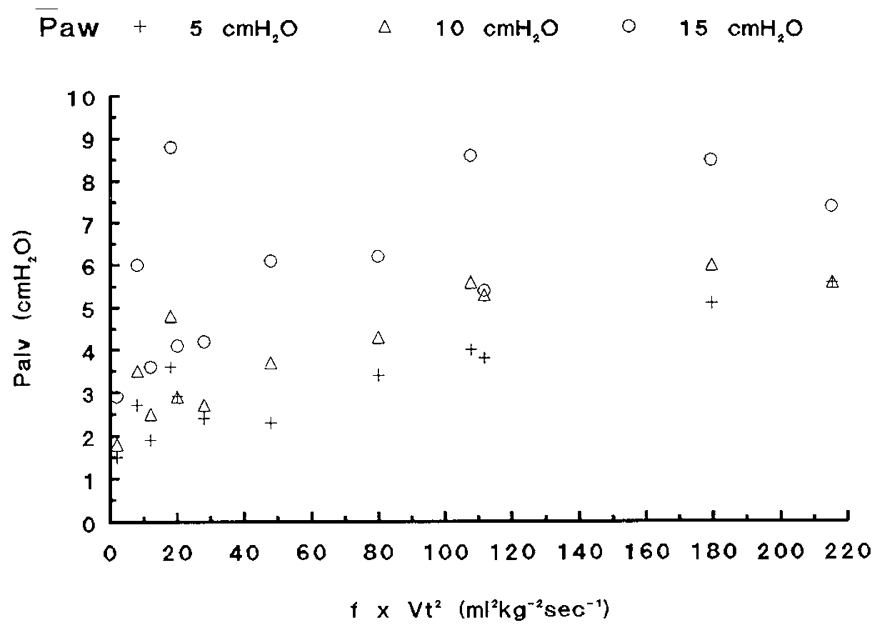

Fig. 4. $\mathrm{P}_{\text {alv }}$ as a function of $\mathrm{f} \times \mathrm{V}_{\mathrm{t}}^{2}$ for $\overline{\mathrm{P}}_{\mathrm{aw}} 5,10,15 \mathrm{~cm} \mathrm{H}_{2} \mathrm{O}$. $\mathrm{FiO}_{2}=$ 0.5 . Each point is the mean of three to five lavaged rabbits.

gas tensions were similar in healthy and lavaged rabbits (Fig. 5), we believe that the lavaged rabbits were lung damaged because greater $\mathrm{P}_{\text {alv }}$ amplitudes were required to obtain these blood gases in lavaged rabbits.

Our $\mathrm{P}_{\text {alv }}$ measurements may not have been representative of "global" $\mathrm{P}_{\text {alv }}$ because the alveolar capsule samples only those units close to the pleural surface in the region of the capsule. Allen et al. (17) have demonstrated marked differences in $P_{\text {alv }}$ between the apex and base and slight differences between the right and left lung at higher frequencies. Fredberg et al. (18) determined that the lung responds in a nonhomogeneous manner to inhaled histamine and they assumed that because frequency dependence of impedance alone cannot explain the regional $\mathrm{P}_{\text {alv }}$ difference, intrinsic regional differences must always exist. Inasmuch as we only measured $\mathrm{P}_{\text {alv }}$ in one location we are unable to comment on $\mathrm{P}_{\text {alv }}$ in other regions of the lung and how they affected oxygenation.

Next we will discuss our blood gas tension results. Our results suggest that the combined effect of a $V_{t}$ of $2 \mathrm{~mL} / \mathrm{kg}$ and a $\bar{P}_{a w}$ greater than or equal to $10 \mathrm{~cm} \mathrm{H}_{2} \mathrm{O}$ are necessary to produce adequate oxygenation. We assume that $\overline{\mathrm{P}}_{\mathrm{aw}}$ improved oxygenation by increasing lung volume and decreasing venous admixture (14). The suboptimal oxygenation that occurs at lower frequencies for $a V_{t}$ of $1 \mathrm{~mL} / \mathrm{kg}$ and $\overline{\mathrm{P}}_{\mathrm{aw}}$ of $5 \mathrm{~cm} \mathrm{H} \mathrm{H}_{2} \mathrm{O}$ (Figs. 1 and 2) is most likely due to a combination of alveolar hypoventilation and increased $\dot{\mathrm{V}}_{\mathrm{A}} / \dot{\mathrm{Q}}$ inequality (5). At the same $\mathrm{V}_{\mathrm{t}}$ and $\overline{\mathrm{P}}_{\mathrm{aw}}$ oxygenation is adequate at higher frequencies. Fletcher and Epstein (1) suspect the increase in minute ventilation at higher frequencies increases mean and end expiratory alveolar pressure, thus improving $\mathrm{PaO}_{2}$ by enhancing ventilation of poorly ventilated alveoli and preventing the closure of small airways (1). We are unable to say if gas trapping occurred at the higher frequencies because we did not measure final lung volume at the higher frequencies.

Others have tried to define "optimal settings" based on $\mathrm{PaCO}_{2}$. Bohn (19) reported the optimal oscillatory frequency to be 15 $\mathrm{Hz}$ because at a fixed stroke volume $(1.9 \mathrm{~mL} / \mathrm{kg})$ this frequency produced the lowest values of $\mathrm{PaCO}_{2}$ over a range of frequencies. However, $V_{t}$ may have fluctuated due to variable losses through the bias flow and due to the frequency dependence of impedance of the animals' respiratory systems. If $V_{t}$ rather than stroke volume was fixed as in our experiment, a different result may have been obtained. Wright et al. (13) obtained the lowest $\mathrm{PaCO}_{2}$ in rabbits with oleic acid lung damage at a frequency of $20 \mathrm{~Hz}$, independent of stroke volume between 2.6 to $8.9 \mathrm{~mL}$. However, they believed that the $\mathrm{Vt}$ decreased at higher frequencies due to



Fig. 5. $\mathrm{PaO}_{2}, \mathrm{PaCO}_{2}, \mathrm{P}_{\text {alv }}$ as functions of frequency at a $\mathrm{V}_{\mathrm{t}}=1 \mathrm{~mL} / \mathrm{kg}$ and $\overline{\mathrm{P}}_{\mathrm{aw}}=10 \mathrm{~cm} \mathrm{H} \mathrm{H}_{2} \mathrm{O}$ in lavaged and healthy rabbits. $\mathrm{FiO}_{2}=0.5$. Each point is the mean of three to five lavaged rabbits \pm SE. 



Fig. 6. $\mathrm{PaO}_{2}$ in lavaged $(A)$ and healthy rabbits $(B)$ as a function of frequency and $\overline{\mathrm{P}}_{\mathrm{aw}}$ at a $\mathrm{V}_{\mathrm{t}}=1 \mathrm{ml} / \mathrm{kg}$. $\mathrm{FiO}_{2}=0.5$. Each point is the mean of three to five rabbits $\pm \mathrm{SE}$.



Fig. 7. $\mathrm{PaO}_{2}$ and $\mathrm{PaCO}_{2}$ as functions of $\mathrm{f} \times \mathrm{V}_{\mathrm{t}}^{2}$ for $\overline{\mathrm{P}}_{\mathrm{aw}} 5,10,15 \mathrm{~cm}$ $\mathrm{H}_{2} \mathrm{O}$. $\mathrm{FiO}_{2}=0.5$. Each point is the mean of three to five healthy rabbits.

gas compression in the apparatus. When $V_{t}$ was corrected for gas compression, they found that $\mathrm{PaCO}_{2}$ decreased with increasing frequency at a constant $V_{t}$ that no longer suggested a frequency optimum. Consistent with Wright's data, we found the lowest $\mathrm{PaCO}_{2}$ (23 torr) at a frequency of $28 \mathrm{~Hz}$ and a $\mathrm{V}_{\mathrm{t}}$ of $2 \mathrm{~mL} / \mathrm{kg}$. Lower values may have been reached if greater frequencies and $V_{t}$ were tested.

Perhaps it is not appropriate to think of an optimal frequency or an optimal $\mathrm{V}_{\mathrm{t}}$ in isolation. Slutsky et al. $(3,4)$ found $\mathrm{CO}_{2}$ elimination to be dependent on $\dot{\mathrm{V}}_{\text {osc }}$ as determined by the product of oscillatory frequency and $V_{t}$. Slutsky concluded that although $\dot{\mathrm{V}}_{\text {osc }}$ is an important factor in determining $\mathrm{CO}_{2}$ elimination, frequency and $V_{t}$ have independent effects with $V_{t}$ having a greater effect on $\mathrm{CO}_{2}$ elimination than frequency at any given $\dot{V}_{\text {osc }}$. In a previous study, we further evaluated this hypothesis by plotting $\mathrm{PaCO}_{2}$ and $\mathrm{PaO}_{2}$ as functions of $\mathrm{f} \times \mathrm{V}_{\mathrm{t}}^{2}$ in healthy rabbits (5). We found that $\mathrm{PaO}_{2}$ and $\mathrm{PaCO}_{2}$ data for many combinations of frequency and $\mathrm{V}_{\mathrm{t}}$ collapsed onto a single curve suggesting that $\mathrm{PaO}_{2}$ and $\mathrm{PaCO}_{2}$ in healthy rabbits are dependent on factors associated with oscillatory flow.

In this study, we plotted $\mathrm{PaO}_{2}$ and $\mathrm{PaCO}_{2}$ as a function of $\mathrm{f} \times$ $\mathrm{V}_{\mathrm{t}}^{2}$ for lavaged rabbits. We found that the $\mathrm{PaO}_{2}$ in lavaged rabbits unlike healthy rabbits initially increased, then decreased as $f \times$ $\mathrm{V}_{\mathrm{t}}^{2}$ increased. The relationship of $\mathrm{PaCO}_{2}$ to $\mathrm{f} \times \mathrm{V}_{\mathrm{t}}^{2}$ was similar in both healthy and lavaged rabbits, decreasing as $f \times V_{t}^{2}$ increased. Our data suggest the highest $\mathrm{PaO}_{2}$ and eucapnic $\mathrm{PaCO}_{2}$ can be obtained at frequencies less than $12 \mathrm{~Hz}$ and $\mathrm{V}_{\mathrm{t}}$ equal to $2 \mathrm{~mL} /$ $\mathrm{kg}$.

We plotted peak-to-peak excursions in $P_{\text {alv }}$ versus $f \times V_{t}^{2}$ to understand the pressure excursions necessary to achieve a given $\mathrm{PaO}_{2}$ and $\mathrm{PaCO}_{2}$ at any frequency and $\mathrm{V}_{\mathrm{t}}$ combination. Although this is clinically relevant, i.e. it tells us what degree of barotrauma may occur at a given combination, a mechanically more appropriate relationship is that of $\mathrm{P}_{\mathrm{alv}}$ versus the product of elastance and tidal volume. Elastance, or its reciprocal, compliance, is dependent on mean distending pressure and has a slight negative frequency dependence. One might thus expect the data in Figures 4 and 8 to collapse onto a single curve if plotted in this fashion, and in fact one can glean such an impression from examination of the figures. We do not have sufficient data to calculate elastance and plot the relationship of interest.

We found that neither $\mathrm{PaO}_{2}$ nor $\mathrm{PaCO}_{2}$ was affected by $\overline{\mathrm{P}}_{\mathrm{aw}}$. Yamada et al. (11) found that as $\overline{\mathrm{P}}_{\mathrm{aw}}$ increased, $\mathrm{PaCO}_{2}$ increased and $\mathrm{PaO}_{2}$ decreased. He associated these findings with decreased alveolar ventilation caused by an increase in the volume of the conducting airways. The difference between our results and those of Yamada may be explained by differences in the animal model studied or because any increase in the volume of the conducting airways of rabbits may have been small compared to the dead space of our ventilator circuit $(7 \mathrm{~mL})$. However, Slutsky et al. (3) predicted that an increase in lung volume could produce two competing phenomena. Increased cross-sectional area of airways may either increase $\mathrm{CO}_{2}$ elimination as a result of increased minute ventilation or decrease $\mathrm{CO}_{2}$ elimination as a result of decreased velocity of flow in the airways resulting in decreased

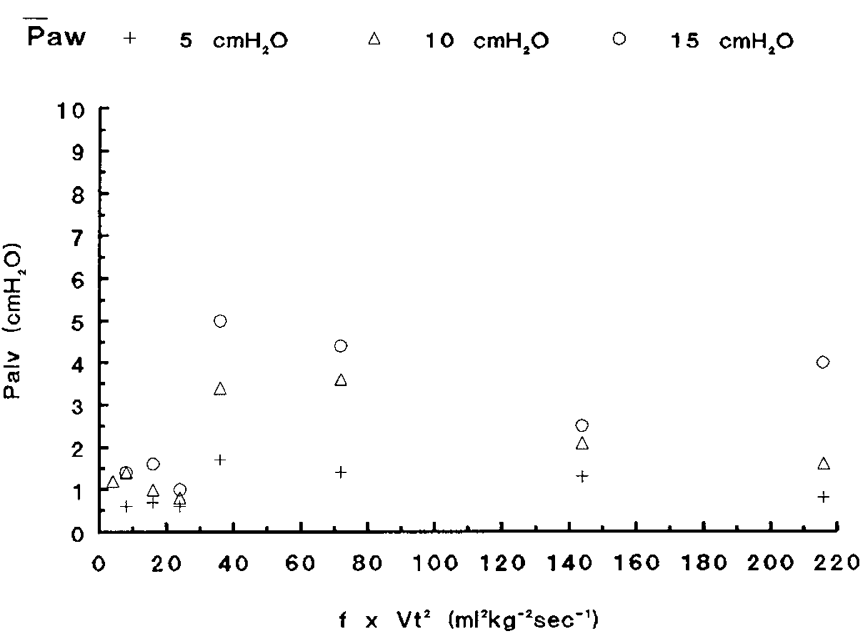

Fig. 8. $\mathrm{P}_{\text {alv }}$ as a function of $\mathrm{f} \times \mathrm{V}_{\mathrm{t}}^{2}$ for $\overline{\mathrm{P}}_{\mathrm{aw}} 5,10,15 \mathrm{~cm} \mathrm{H}_{2} \mathrm{O}$. $\mathrm{FiO}_{2}=$ 0.5 . Each point is the mean of three to five healthy rabbits 
gas mixing. Korvenranta et al. (20) found that $\mathrm{CO}_{2}$ elimination increased as $\mathrm{V}_{\mathrm{t}}$ increased up to $3 \mathrm{~mL} / \mathrm{kg}$. For $\mathrm{V}_{\mathrm{t}}>3 \mathrm{~mL} / \mathrm{kg} \mathrm{CO}$ elimination began to decrease as a result of inadvertent positive end-expiratory pressure resulting from increased gas trapping. When inadvertent positive end-expiratory pressure was held constant at 5 or $10 \mathrm{~cm} \mathrm{H} \mathrm{H}_{2} \mathrm{O}, \mathrm{CO}_{2}$ elimination increased as $\mathrm{V}_{1}$ increased, a finding more consistent with our results.

We were surprised to find that healthy and lavaged rabbits were similar in their blood gas response to changes in frequency, $V_{t}$ and $\overline{\mathrm{P}}_{\mathrm{aw}}$. We expected our results to show that increasing $\overline{\mathrm{P}}_{\mathrm{aw}}$, in lavaged rabbits would improve oxygenation compared to healthy rabbits. Kolton et al. (12) and Lachmann et al. (15) demonstrated that FRC decreases after lavage. We have previously shown that increasing lung volume in lavaged rabbits decreases venous admixture and improves oxygenation (14). Healthy and lavaged rabbits may not have differed with respect to effects of $\overline{\mathrm{P}}_{\mathrm{aw}}$ because $5 \mathrm{~cm} \mathrm{H}_{2} \mathrm{O}$, the lowest value studied, may have exceeded closing pressure for the lavaged animals, or because the inflation maneuver between changes of settings may have transiently eliminated differences in lung volume. If the animals were maintained at a $\overline{\mathrm{P}}_{\mathrm{aw}}=5 \mathrm{~cm} \mathrm{H} \mathrm{H}_{2} \mathrm{O}$ for longer periods of time before blood gas specimens were obtained, they may develop atelectasis and decreased $\mathrm{PaO}_{2}$.

Our findings have several important clinical implications. First, both oxygenation and carbon dioxide tension depend on $f$ $\times V_{t}^{2}$ such that several combinations of frequency and $V_{t}$ may result in similar gas exchange. Second, $\mathrm{P}_{\text {alv }}$ amplitude depends on both $f \times V_{t}^{2}$ and $\bar{P}_{a w}$. Thus, to optimize gas exchange while minimizing pulmonary barotrauma, one may wish to choose the lowest possible $\overline{\mathrm{P}}_{\mathrm{aw}}$ and $\mathrm{f} \times \mathrm{V}_{\mathrm{t}}^{2}$ product resulting in adequate gas exchange.

In conclusion, we did not find one combination of frequency, $V_{t}$, and $\bar{P}_{a w}$ that simultaneously provided the lowest alveolar pressure amplitude and physiologic blood gas tensions. Our results indicate that trade offs for either more desirable blood gas tensions or lower airway pressure swings are necessary. In the animals studied, the combination of frequency, $V_{t}$ and $\overline{\mathrm{P}}_{\mathrm{aw}}$ that provided the greatest $\mathrm{PaO}_{2}, \mathrm{PaCO}_{2}$ between 35-55 torr, and a low $\mathrm{P}_{\text {alv }}$ were frequencies less than $12 \mathrm{~Hz}, \mathrm{a} \mathrm{V}$ of $2 \mathrm{~mL} / \mathrm{kg}$ and a $\overline{\mathrm{P}}_{\mathrm{aw}}$ of $10 \mathrm{~cm} \mathrm{H}_{2} \mathrm{O}$. Higher frequencies may be useful in lowering $\mathrm{PaCO}_{2}$ in subjects with more severe lung disease but as the product $\mathrm{f} \times \mathrm{V}_{\mathrm{t}}^{2}$ increases, $\mathrm{PaO}_{2}$ may decrease and alveolar pressure amplitude may increase. Healthy and lavaged rabbits were similar in that as frequency increased at lower $\mathrm{V}_{\mathrm{t}}, \mathrm{PaO}_{2}$ increased and $\mathrm{PaCO}_{2}$ decreased. They differed in that as frequency increased at higher $\mathrm{V}_{\mathrm{t}}, \mathrm{PaO}_{2}$ decreased in lavaged but not healthy rabbits.
$\mathrm{P}_{\text {alv }}$ was slightly greater in lavaged rabbits to maintain similar blood gas tensions, but this was not statistically significant.

\section{REFERENCES}

1. Fletcher PR, Epstein RA 1982 Constancy of physiological dead space during high-frequency ventilation. Respir Physiol 47:39-49

2. Rieke H, Hook CL, Meyer M 1983 Pulmonary gas exchange during highfrequency ventilation in dogs. Respir Physiol 54:1-17

3. Slutsky AS, Kamm RD, Rossing TH, Loring SH, Lehr J, Shapiro AH, Ingram Jr RH, Drazen JM 1981 Effects of frequency, tidal volume, and lung volume on $\mathrm{CO}_{2}$ elimination in dogs by high frequency $(2-30 \mathrm{~Hz})$, low tidal volume ventilation. J Clin Invest 68:1475-1484

4. Watson JW, Jackson AC, Gillespie JR $1984 \mathrm{CO}_{2}$ elimination and airway opening pressure during high frequency oscillation in dogs. Respir Physiol $58: 235-244$

5. Boynton BR, Fredberg JJ, Buckley BG, Frantz ID 1989 Gas exchange in healthy rabbits during high-frequency oscillatory ventilation. J Appl Physiol 66:1343-1351

6. Permutt S, Mitzner W, Weinmann G 1985 Model of gas transport during highfrequency ventilation. J Appl Physiol 58:1956-1970

7. Brusasco V, Rehder K, Beck KC, Crawford M 1985 Gas volume delivered by high frequency ventilation. Fed Proc 44:1383(abstr)

8. Fredberg JJ, Keefe DH, Glass GM, Castile RC, Frantz ID 1984 Alveolar pressure nonhomogeneity during small-amplitude high-frequency oscillation. J Appl Physiol 57:788-800

9. Simon BA, Weinmann GG, Mitzner W 1984 Mean airway pressure and alveolar pressure during high-frequency ventilation. J Appl Physiol 57:10691078

10. Allen JL, Fredberg JJ, Keefe DH, Frantz ID 1985 Alveolar pressure magnitude and asynchrony during high frequency oscillation of excised rabbit lungs. Am Rev Respir Dis 132:343-349

11. Yamada Y, Venegas JG, Strieder DJ, Hales CA 1986 Effects of mean airway pressure on gas transport during high-frequency ventilation in dogs. $\mathrm{J}$ Appl Physiol 61:1896-1902

12. Kolton M, Cattran CB, Kent G, Volgyesi G, Froese AB, Bryan AC 1982 Oxygenation during high-frequency ventilation compared with conventional ventilation in two models of lung injury. Anesth Anal 61:323-332

13. Wright K, Lyrene RK, Truog WE, Standaert TA, Murphy J, Woodrum DE 1981 Ventilation by high-frequency oscillation in rabbits with oleic acid lung disease. J Appl Physiol 50:1056-1060

14. Boynton BR, Buckley BG, Villanueva D, Vreeland P, Kamitsuka MD, Frantz ID 1988 Effect of mean airway pressure on gas exchange during high frequency oscillatory ventilation. Pediatr Res 23:499A(abstr)

15. Lachmann B, Robertson B, Vogel J 1980 In vivo lung lavage as an experimental model of the respiratory distress syndrome. Acta Anaesthesiol 24:231-236

16. Frantz ID, Close RH 1985 Alveolar pressure swings during high frequency ventilation in rabbits. Pediatr Res 19:162-166

17. Allen JL, Frantz ID, Fredberg JJ 1987 Heterogeneity of mean alveolar pressure during high-frequency oscillations. J Appl Physiol 62:223-228

18. Fredberg JJ, Ingram RH, Castile RG, Glass GM, Drazen JM 1985 Nonhomogeneity of lung response to inhaled histamine assessed with alveolar capsules. J Appl Physiol 58:1914-1922

19. Bohn DJ, Miyasaka K, Marchak BE, Thompson WK, Froese AB, Bryan AC 1980 Ventilation by high-frequency oscillation. J Appl Physiol 48:710-716

20. Korvenranta H, Carlo WA, Goldthwait DA, Fanaroff AA 1987 Carbon dioxide elimination during high-frequency jet ventilation. J Pediatr 111:107-113 